\title{
High Serum Alkaline Phosphatase, Hypercalcaemia, Race, and Mortality in South African Maintenance Haemodialysis Patients
}

\author{
Bala Waziri, Raquel Duarte, and Saraladevi Naicker \\ Department of Internal Medicine, Faculty of Health Sciences, University of the Witwatersrand, Johannesburg, South Africa \\ Correspondence should be addressed to Bala Waziri; balawaziri@gmail.com
}

Received 1 October 2016; Revised 12 November 2016; Accepted 14 December 2016; Published 12 January 2017

Academic Editor: Jaime Uribarri

Copyright (C) 2017 Bala Waziri et al. This is an open access article distributed under the Creative Commons Attribution License, which permits unrestricted use, distribution, and reproduction in any medium, provided the original work is properly cited.

\begin{abstract}
Objective. To determine the association between serum total alkaline phosphatase (TAP) and mortality in African maintenance haemodialysis patients (MHD). Patients and Methods. The study enrolled a total of 213 patients on MHD from two dialysis centers in Johannesburg between January 2009 and March 2016. Patients were categorized into a low TAP group $(\leq 112$ U/L) versus a high TAP group (>112 U/L) based on a median TAP of 112 U/L. Results. During the follow-up period of 7 years, there were 55 (25.8\%) deaths. After adjusting for cofounders such as age, other markers of bone disorder, and comorbidity (diabetes mellitus), patients in the high TAP group had significantly higher risk of death compared to patients in the low TAP group (hazard ratio, 2.50 ; $95 \%$ CI 1.24-5.01, $P=0.01$ ). Similarly, serum calcium $>2.75 \mathrm{mmol} / \mathrm{L}$ was associated with increased risk of death compared to patients within levels of $2.10-2.37 \mathrm{mmol} / \mathrm{L}$ (HR 6.34, 95\% CI 1.40-28.76; $P=0.02$ ). The HR for death in white patients compared to black patients was $6.88 ; 95 \%$ CI 1.82-25.88; $P=0.004$. Conclusion. High levels of serum alkaline phosphatase, hypercalcaemia, and white race are associated with increased risk of death in MHD patients.
\end{abstract}

\section{Introduction}

Prior to the availability of commercial intact parathyroid hormone (PTH) assays, serum total alkaline phosphatase (TAP) measurements were used as one of the surrogate markers of high bone turnover that was utilized in the management of chronic kidney disease mineral and bone disorder (CKDMBD) [1]. Subsequently, in 2003 the Kidney Disease Outcome Quality Initiative (KDOQI) guidelines on CKD-MBD made no recommendations regarding the use of alkaline phosphatase and this has made it a less preferred marker to PTH. However, in 2009 the Kidney Disease Improving Global Outcomes (KDIGO) guidelines recommended measurement of TAP every 12 months in CKD 4-5D [2] and more recently evidence continued to emerge on the importance of higher levels of alkaline phosphatase in the pathogenesis of vascular calcification via hydrolysis of pyrophosphate which is a potent inhibitor of vascular calcification [3-5]. This was further supported by a study that showed elevated levels of alkaline phosphatase, independent of $\mathrm{PTH}$, calcium, or phosphorus as predictor of coronary artery calcification in haemodialysis patients [6]. Interestingly, in a recent secondary analysis of the handling erythropoietin resistance with oxypentifylline (HERO) trial, high levels of alkaline phosphatase were also associated with erythropoietin stimulating agent hyporesponsiveness [7]. These findings may likely explain the unclear pathophysiologic link between high serum alkaline phosphatase and mortality in haemodialysis patients [6].

Although the role of racial disparities in adverse clinical outcomes remains controversial and inconclusive, some studies have demonstrated survival benefits attributable to race in patients undergoing MHD $[8,9]$. In addition, the impact of these biochemical abnormalities have been shown to differ across race and thus the need for race specific target values for these markers of mineral bone disorder $[10,11]$.

Therefore, the aim of this study was to determine if there is a link between high serum alkaline phosphatase and mortality in African MHD patients.

\section{Patients and Methods}

This study was a retrospective review of patients undergoing MHD from two dialysis centers in Johannesburg between 
January 2009 and March 2016. A total of 213 patients aged $\geq 18$ years with available baseline line variables of interest were included. Exclusion criteria included patients with missing important data for analysis, being on dialysis for less than three months, having active or chronic liver disease, and having malignancies. In addition, we excluded Indian and mixed races to allow for a proper comparison between black and white patients. Retrieved data included patients' demographic characteristics, blood pressure measurements, duration on haemodialysis, comorbid disease, and medication history related to CKD-MBD. Determination of race was based on self-report by the participants.

Patients were categorized into the low TAP group $(\leq 112 \mathrm{U} / \mathrm{L})$ versus the high TAP group $(>112 \mathrm{U} / \mathrm{L})$ based on median TAP level of $112 \mathrm{U} / \mathrm{L}$. Secondary analysis involved exploring the relationship between race, other markers of mineral bone disorder, and primary outcome. In line with a previous study [12] total calcium levels were categorized into four categories with the KDOQI target range as the reference category. Based on the KDIGO CKD-MBD guidelines, PTH was divided into three categories.

The primary outcome of this study was death and events other than death were censored and this included kidney transplantation, loss to follow-up, or still undergoing haemodialysis at the end of the study.

2.1. Laboratory Measurements. Patients' baseline biochemical parameters (within the first three months of initiating dialysis) were assessed. Most of the biochemical markers were measured monthly except for quarterly PTH. Plasma intact PTH was measured by an electrochemiluminescence immunoassay (ECLIA) run on a Cobas 6000 autoanalyzer (Roche Diagnostics, Mannheim, Germany; reference range $10-65 \mathrm{pg} / \mathrm{mL}$ ). Serum $25-\mathrm{OH}$ vitamin D was measured by a chemiluminescent microparticle immunoassay (CMIA) technique run on the ARCHITECT C8000 autoanalyzer (Abbott Laboratories, Abbott Park, IL, US). Reference ranges are as follows: $<10 \mathrm{ng} / \mathrm{mL}$ as severe deficiency, $10-29 \mathrm{ng} / \mathrm{mL}$ as moderate deficiency, $30-100 \mathrm{ng} / \mathrm{mL}$ as sufficiency, and $>100 \mathrm{ng} / \mathrm{mL}$ as toxic.

Serum calcium, phosphate, and alkaline phosphatase were measured using the ARCHITECT C8000 autoanalyzer (Abbot Laboratories, Abbott Park, IL, US). The corrected calcium was determined using the formula: corrected calcium $(\mathrm{mmol} / \mathrm{L})=$ calcium measured $(\mathrm{mmol} / \mathrm{L})+0.02[40-$ albumin $(\mathrm{g} / \mathrm{L})]$. Total alkaline phosphatase reference range is 53-128 U/L.

Plasma albumin was measured by colorimetric (bromocresol green) method on a Cobas 6000 autoanalyzer (Roche Diagnostics, Mannheim, Germany; reference range 35$52 \mathrm{~g} / \mathrm{L})$.

Other biochemical parameters were determined using routine laboratory techniques.

Blood samples were generally collected predialysis at midweek with the exception of the postdialysis serum urea for kinetic modeling.
Calculation of normalized protein catabolic rate was based on the formula [13], $\mathrm{nPCR}=(0.136 \times F)+0.251$, where $F=\mathrm{Kt} / \mathrm{V} \times([$ predialysis $\mathrm{BUN}+$ postdialysis BUN $] \div 2)$.

2.2. Statistical Analyses. Pearson's or Fisher's exact test was utilized for proportion comparisons. Continuous variables are presented as means \pm standard deviations or median and interquartile range (IQR) as appropriate. Associations between serum alkaline phosphatase and other biochemical parameters were assessed by multiple linear regression analyses. The Cox proportional model was used to determine the crude and adjusted hazard ratios of death for different categories of serum alkaline phosphatase, calcium, $\mathrm{PTH}$, phosphate, $25-\mathrm{OH}$ vitamin $\mathrm{D}$, and white versus black patients. Patients' demographic and baseline characteristics were compared between the low and high total alkaline phosphatase groups as well as white versus black patients, using an independent $t$-test and Mann-Whitney $U$ test for normally distributed and nonnormally distributed variables, respectively. One-way ANOVA and Kruskal-Wallis tests were used to compare normally and nonnormally distributed continuous variables across categories of serum calcium.

A $P$ value of less than 0.05 was considered statistically significant at the $95 \%$ confidence interval. All analyses were performed using STATA version 12 (STATA Corp., TX, USA).

\section{Results}

The study included two hundred and thirteen patients (137 men, 76 women) undergoing MHD. The mean $( \pm \mathrm{SD})$ of age, median dialysis vintage, and mean $\mathrm{Kt} / \mathrm{V}$ were $54.5 \pm 15.6$ years, 24 months (IQR, 12-48), and $1.44 \pm 0.3$, respectively. The majority of the patients were on three times weekly, $4 \mathrm{hr}$ sessions of haemodialysis. Most of the patients were dialyzed with a dialysate calcium concentration of $1.50 \mathrm{mmol} / \mathrm{L}$, which is usually modified based on serum levels of calcium. The blood and dialysis flow rates are generally $300-400 \mathrm{mls} / \mathrm{min}$ and $500 \mathrm{mls} / \mathrm{min}$, respectively. However, these values varied according to patient's blood pressure and haemodynamic state. A native arteriovenous fistula was used in more than half of the study population (60.6\%). Almost all patients (93.0\%) were on ESAs.

Table 1 shows the comparisons of baseline clinical characteristics between patients in high TAP and low TAP groups. The low alkaline phosphatase group had significantly higher mean age than the high TAP group. Other parameters were comparable between the groups. For the management of CKD-MBD, $76.9 \%$ of the patients were on calcium carbonate and $64.3 \%$ on alfacalcidol with a similar distribution of drug usage across the groups. The study population included 120 (56.3\%) black and 93 (43.7\%) white patients. The mean age, hemoglobin concentration, albumin, and phosphate levels were significantly higher in white compared to black patients. $56(26.3 \%)$ of the study population had diabetes and the proportion was higher in black patients (30.0\% versus $21.5 \%$, $P=0.02)$ (Table 2).

The characteristics of the patients across different categories of serum calcium levels are shown in Table 3. Patients 
TABLE 1: Comparisons of baseline characteristics between patients in high TAP and low TAP groups.

\begin{tabular}{|c|c|c|c|c|}
\hline Characteristic & All $(N=213)$ & TAP $\leq 112(n=98)$ & TAP $>112(n=115)$ & $P$ value \\
\hline Age (years) & $54.53 \pm 15.62$ & $57.3 \pm 15.5$ & $51.1 \pm 15.1$ & 0.008 \\
\hline Female, $n(\%)$ & $76(35.7 \%)$ & $35(35.7 \%)$ & $41(35.7 \%)$ & 0.25 \\
\hline Diabetes, $n(\%)$ & $56(26.3 \%)$ & $27(27.6 \%)$ & $29(25.2 \%)$ & 0.76 \\
\hline Weight (Kg) & $71 \pm 9.6$ & $70 \pm 9.5$ & $69 \pm 9.6$ & 0.53 \\
\hline $\mathrm{BMI}\left(\mathrm{Kg} / \mathrm{m}^{2}\right)$ & $24.7 \pm 0.9$ & $24.9 \pm 1.0$ & $24.5 \pm 1.6$ & 0.83 \\
\hline Dialysis vintage (months) & $24(12-48)$ & $36(12-60)$ & $36(12-48)$ & 0.55 \\
\hline Systolic Bp (mmHg) & $134 \pm 21.8$ & $135.5 \pm 19.6$ & $133.5 \pm 24.4$ & 0.38 \\
\hline Diastolic Bp (mmHg) & $72.0 \pm 13.73$ & $70.7 \pm 12.0$ & $74.1 \pm 13.8$ & 0.86 \\
\hline Haemoglobin (g/dL) & $10.3 \pm 2.0$ & $10.2 \pm 1.9$ & $9.9 \pm 2.1$ & 0.10 \\
\hline Potassium (mmol/L) & $4.62 \pm 0.8$ & $4.6 \pm 0.9$ & $4.6 \pm 0.8$ & 0.55 \\
\hline Calcium (mmol/L) & $2.25 \pm 0.14$ & $2.32 \pm 0.30$ & $2.34 \pm 0.29$ & 0.58 \\
\hline Corrected calcium (mmol/L) & $2.40 \pm 0.25$ & $2.50 \pm 0.22$ & $2.50 \pm 0.21$ & 0.42 \\
\hline iPTH (pg/mL) & $307(148-656)$ & $246(137-527)$ & $325(152-693)$ & 0.09 \\
\hline Phosphate (mmol/L) & $1.59 \pm 0.6$ & $1.60 \pm 0.6$ & $1.40 \pm 0.6$ & 0.07 \\
\hline $25-\mathrm{OH}$ vitamin $\mathrm{D}$ (ng/mL) & $21.16 \pm 10.71$ & $20.4 \pm 8.8$ & $22.2 \pm 12.9$ & 0.83 \\
\hline Alkaline phosphatase (U/L) & $112(74-163)$ & $74(62-96)$ & $163(130-223)$ & $<0.001$ \\
\hline Albumin (g/L) & $31.9 \pm 6.0$ & $32.6 \pm 5.4$ & $30.3 \pm 6.5$ & 0.98 \\
\hline \multicolumn{5}{|l|}{ Type of vascular access } \\
\hline Arteriovenous fistula & $129(60.6 \%)$ & $65(66.3 \%)$ & $64(55.7 \%)$ & 0.23 \\
\hline Graft & $39(18.3 \%)$ & $23(23.5 \%)$ & $26(22.6 \%)$ & 0.88 \\
\hline Catheter & $45(21.1 \%)$ & $21(21.4 \%)$ & $24(20.9 \%)$ & 0.97 \\
\hline Alanine transaminase $(\mathrm{U} / \mathrm{L})$ & $21.1 \pm 8.9$ & $17.6 \pm 8.7$ & $22.9 \pm 8.8$ & 0.20 \\
\hline $\mathrm{Kt} / \mathrm{V}$ & $1.44 \pm 0.28$ & $1.4 \pm 0.3$ & $1.4 \pm 0.2$ & 0.72 \\
\hline n PCR (g/kg/day) & $1.10 \pm 0.24$ & $1.02 \pm 0.30$ & $1.08 \pm 0.27$ & 0.56 \\
\hline T. cholesterol (mmol/L) & $4.18 \pm 0.91$ & $4.3 \pm 0.9$ & $4.1 \pm 0.9$ & 0.14 \\
\hline \multicolumn{5}{|l|}{ Medications } \\
\hline Calcium carbonate, $n(\%)$ & $163(76.5 \%)$ & $77(78.6 \%)$ & $86(74.7 \%)$ & 0.74 \\
\hline Alfacalcidol, $n(\%)$ & $137(64.3 \%)$ & $61(62.2 \%)$ & $76(66.1 \%)$ & 0.55 \\
\hline ESA $n(\%)$ & $198(93.0 \%)$ & $94(95.9)$ & $104(90.4 \%)$ & 0.50 \\
\hline ESA dose (U/week) & $13373 \pm 4205$ & $13714 \pm 4768$ & $12957 \pm 3457$ & 0.53 \\
\hline
\end{tabular}

Continuous variables are presented as means \pm standard deviations or median (interquartile range) and categorical data as frequencies (percentages), $\mathrm{BP}=$ blood pressure, $\mathrm{i}$ PTH $=$ intact parathyroid hormone, $\mathrm{TAP}=$ total alkaline phosphatase, $\mathrm{ESA}=$ erythropoietin stimulating agent, $\mathrm{n} \mathrm{PCR}=$ normalized protein catabolic rate, and BMI = body mass index.

in the highest category of calcium levels had significantly lower mean serum creatinine, and a few of them were on calcium carbonate and alfacalcidol. No significant differences were found in other parameters of the patients across the serum calcium categories. The overall mean dialysate calcium was $1.65 \pm 0.24 \mathrm{mmol} / \mathrm{L}$ and patients with higher levels of calcium are more likely to be dialyzed with lower dialysate calcium concentration. To further explore our practice pattern regarding treatment of hypercalcaemia, available data revealed that only 5 patients in the highest category of calcium had undergone a parathyroidectomy while the majority of them were dialyzed with $1.25 \mathrm{mmol} / \mathrm{L}$ of dialysate calcium concentration and had their calcium carbonate and alfacalcidol discontinued.

During a follow-up period of 7 years there were 57 (26.8\%) deaths. After adjusting for cofounders such as age, other markers of bone disorder (calcium, phosphate, and $\mathrm{PTH}$ ), serum alanine transaminase, $25-\mathrm{OH}$ vitamin $\mathrm{D}$, and comorbidity (diabetes mellitus), patients in the high TAP group had a significantly higher risk of death compared to patients in the low TAP group (hazard ratio, 2.5; 95\% CI 1.245.01, $\log \operatorname{rank} P=0.01$ ).

Patients in the highest category of corrected calcium $(>2.75 \mathrm{mmol} / \mathrm{L})$ had more than a sixfold increased risk of death compared to patients with normal calcium (HR 6.34, 95\% CI 1.40-28.76; $P=0.02$ ). Similarly, we found a significant association between race and mortality, in which white patients had an accentuated six fold increase in adjusted hazard ratio for death compared to black patients (HR 6.88, 95\% CI 1.82-25.88; $P=0.004$ ) (Table 4). Figures 1, 2, and 3 show Kaplan Meir Survival curves for TAP, race, and calcium levels, respectively.

Univariate linear regression analysis revealed a significant association between TAP and age $\left(r^{2}=0.04, P=0.008\right)$, corrected calcium $\left(r^{2}=0.03, P=0.04\right)$, and PTH $\left(r^{2}=\right.$ $0.04, P=0.006)$. In multivariate regression analyses $\mathrm{PTH}$ 
TABLE 2: Baseline characteristics of study population by race.

\begin{tabular}{|c|c|c|c|c|}
\hline Parameters & All $(n=213)$ & Black $(n=120)$ & White $(n=93)$ & $P$ value \\
\hline Age (years) & $54.53 \pm 15.62$ & $51.0 \pm 14.6$ & $58.7 \pm 15.9$ & $<0.001$ \\
\hline Haemoglobin (g/dL) & $10.3 \pm 2.00$ & $9.9 \pm 1.98$ & $10.7 \pm 1.94$ & 0.004 \\
\hline Systolic Bp (mmHg) & $134 \pm 21.8$ & $130 \pm 20.3$ & $139 \pm 22.8$ & 0.98 \\
\hline PTH (pg/mL) & $307(148-656)$ & $327(137-658)$ & $290(149-618)$ & 0.97 \\
\hline Calcium (mmol/L) & $2.28 \pm 0.22$ & $2.26 \pm 0.22$ & $2.30 \pm 0.21$ & 0.94 \\
\hline Phosphate (mmol/L) & $1.59 \pm 0.56$ & $1.49 \pm 0.57$ & $1.71 \pm 0.53$ & 0.004 \\
\hline Albumin (g/L) & $31.9 \pm 6.0$ & $30.8 \pm 6.5$ & $33.04 \pm 5.5$ & 0.03 \\
\hline $25(\mathrm{OH})$ vitamin $\mathrm{D}(\mathrm{ng} / \mathrm{mL})$ & $21.16 \pm 10.71$ & $20.57 \pm 9.79$ & $21.80 \pm 11.67$ & 0.77 \\
\hline TAP (U/L) & $112(74-163)$ & $110(75-151)$ & $115(71-164)$ & 0.33 \\
\hline T. cholesterol (mmol/L) & $4.2 \pm 0.8$ & $4.0 \pm 0.9$ & $4.1 \pm 0.9$ & 0.05 \\
\hline Diabetes, $n(\%)$ & $56(26.3 \%)$ & $36(30.0 \%)$ & $20(21.5 \%)$ & 0.02 \\
\hline Male, $n(\%)$ & $137(64.3 \%)$ & $72(60.0 \%)$ & $65(69.9 \%)$ & 0.07 \\
\hline $\mathrm{Kt} / \mathrm{V}$ & $1.44 \pm 0.3$ & $1.41 \pm 0.3$ & $1.46 \pm 0.30$ & 0.40 \\
\hline
\end{tabular}

Continuous variables are presented as means \pm standard deviations or median (interquartile range) and categorical data as frequencies (percentages). $\mathrm{BP}=$ blood pressure, TAP = total alkaline phosphatase, and PTH = parathyroid hormone.

TABle 3: Patient characteristics by serum calcium categories.

\begin{tabular}{|c|c|c|c|c|c|}
\hline Parameters & $\begin{array}{c}<2.10 \mathrm{mmol} / \mathrm{L} \\
\quad(n=31)\end{array}$ & $\begin{array}{c}2.10-2.37 \mathrm{mmol} / \mathrm{L} \\
(n=92)\end{array}$ & $\begin{array}{c}2.38-2.75 \mathrm{mmol} / \mathrm{L} \\
(n=57)\end{array}$ & $\begin{array}{c}>2.75 \mathrm{mmol} / \mathrm{L} \\
\quad(n=33)\end{array}$ & $P$-value \\
\hline Age (years) & $50.9 \pm 15.0$ & $52.9 \pm 15.0$ & $58.3 \pm 16.4$ & $56.5 \pm 26.1$ & 0.09 \\
\hline Systolic Bp (mmHg) & $130.9 \pm 18.6$ & $138.8 \pm 21.5$ & $139.8 \pm 30.7$ & $138.9 \pm 21.5$ & 0.18 \\
\hline Diastolic Bp (mmHg) & $71.2 \pm 15.3$ & $71.7 \pm 11.2$ & $76.4 \pm 18.9$ & $71.2 \pm 11.1$ & 0.38 \\
\hline Haemoglobin (g/dL) & $10.8 \pm 2.4$ & $10.2 \pm 1.9$ & $10.1 \pm 1.9$ & $8.15 \pm 1.9$ & 0.20 \\
\hline Albumin g/L & $32.0 \pm 5.2$ & $32.7 \pm 6.0$ & $30.5 \pm 6.6$ & $29.5 \pm 5.0$ & 0.26 \\
\hline T.chol (mmol/L) & $4.3 \pm 1.0$ & $4.2 \pm 0.9$ & $4.2 \pm 0.9$ & $4.1 \pm 0.9$ & 0.97 \\
\hline $25-\mathrm{OH}$ vitamin $\mathrm{D}(\mathrm{ng} / \mathrm{mL})$ & $22.8 \pm 9.1$ & $22.0 \pm 10.4$ & $18.1 \pm 8.1$ & $15.8 \pm 3.5$ & 0.11 \\
\hline PTH (pg/mL) & $568.8 \pm 334.8$ & $458.64 \pm 424.4$ & $366.2 \pm 405.1$ & $254.0 \pm 103.2$ & 0.01 \\
\hline Phosphate (mmol/L) & $1.5 \pm 0.6$ & $1.6 \pm 0.6$ & $1.5 \pm 0.5$ & $1.6 \pm 0.5$ & 0.66 \\
\hline Creatinine $(\mu \mathrm{mol} / \mathrm{L})$ & $822.5 \pm 261.0$ & $734.4 \pm 283.2$ & $592.5 \pm 245.5$ & $489.5 \pm 355.7$ & 0.002 \\
\hline $\mathrm{Kt} / \mathrm{V}$ & $1.4 \pm 0.2$ & $1.5 \pm 0.3$ & $1.4 \pm 0.3$ & $1.4 \pm 0.4$ & 0.33 \\
\hline Dialysis vintage (months) & $31.3 \pm 23.0$ & $34.2 \pm 23.0$ & $30.9 \pm 21.1$ & $30.0 \pm 8.9$ & 0.80 \\
\hline Dialysate calcium (mmol/L) & $1.65 \pm 0.24$ & $1.63 \pm 0.14$ & $1.63 \pm 0.14$ & $1.54 \pm 0.24$ & 0.50 \\
\hline $\mathrm{DM}, n$ & 13 & 15 & 17 & 11 & 0.40 \\
\hline \multicolumn{6}{|l|}{ Medications } \\
\hline Calcium carbonate $n(\%)$ & $30(96.8 \%)$ & $79(85.7 \%)$ & $41(71.9 \%)$ & $13(39.4 \%)$ & $<0.001$ \\
\hline Alfacalcidol $n(\%)$ & $28(90.3 \%)$ & $63(68.4 \%)$ & $35(61.4 \%)$ & $11(33.3 \%)$ & $<0.001$ \\
\hline
\end{tabular}

Continuous variables are presented as means \pm standard deviations or median (interquartile range) and categorical data as frequencies (percentages). $\mathrm{BP}=$ blood pressure, PTH = parathyroid hormone, $P$ values derived by one-way ANOVA, and Kruskal-Wallis tests for continuous variables and Chi-squared for categorical variables. Serum categories based on KDOQI reference range.

and calcium remained significantly correlated with TAP, $P=$ 0.006 and 0.04 , respectively.

\section{Discussion}

Several studies from Europe, America, and Asia have consistently shown a linear relationship between high serum alkaline phosphate and mortality in the haemodialysis population [14-17], while results relating to other markers of mineral metabolism revealed nonlinear (U or J patterns) associations
$[12,18,19]$. Such data relating to the impact of markers of CKD-MBD on mortality in African MHD patients are lacking. In this present study, higher levels of TAP, hypercalcaemia, and white race were associated with increased risk of death. These findings are consistent with other large studies where higher levels of TAP were independently associated with higher risk of mortality [14, 17].

Interestingly, this association was also reported in CKD patients as well as in the general population [20, 21]. The National Health and Nutrition Examination Survey (NHANES) data revealed an independent association 
TABLE 4: Crude and adjusted hazard ratio (95\% CI) of primary outcome by baseline characteristics.

\begin{tabular}{|c|c|c|c|c|c|c|}
\hline Parameter & Crude HR & $95 \% \mathrm{CI}$ & $P$ & Adjusted HR & $95 \% \mathrm{CI}$ & $P$ \\
\hline TAP > $112 \mathrm{U} / \mathrm{L}$ & 2.20 & $1.12-4.32$ & 0.02 & 2.50 & $1.24-5.01$ & 0.01 \\
\hline \multicolumn{7}{|l|}{ Calcium (mmol/L) } \\
\hline$<2.10$ & 0.66 & $0.32-1.35$ & 0.26 & 0.97 & $0.22-4.26$ & 0.97 \\
\hline$\geq 2.10-\leq 2.37$ & 1.00 & Reference & & & & \\
\hline$>2.37-\leq 2.75$ & 2.31 & $1.20-4.44$ & 0.02 & 1.54 & $0.57-4.18$ & 0.39 \\
\hline$>2.75$ & 6.82 & $1.55-30.1$ & 0.01 & 6.34 & $1.40-28.76$ & 0.02 \\
\hline \multicolumn{7}{|l|}{ PTH (pg/mL) } \\
\hline$<130$ & 1.00 & Reference & & & & \\
\hline$\geq 130-\leq 585$ & 1.26 & $0.57-2.79$ & 0.56 & 2.77 & $0.61-12.58$ & 0.19 \\
\hline$\geq 585$ & 1.05 & $0.44-2.49$ & 0.92 & 2.22 & $0.42-11.65$ & 0.35 \\
\hline Phosphate $>1.50 \mathrm{mmol} / \mathrm{L}$ & 1.09 & $0.61-1.95$ & 0.77 & 1.43 & $0.47-4.40$ & 0.53 \\
\hline $25 \mathrm{OH}$ vitamin $\mathrm{D} \leq 30 \mathrm{ng} / \mathrm{mL}$ & 2.21 & $0.66-7.35$ & 0.19 & 1.07 & $0.23-4.79$ & 0.92 \\
\hline White race & 1.69 & $0.95-3.04$ & 0.08 & 6.88 & $1.82-25.88$ & 0.004 \\
\hline
\end{tabular}

$\mathrm{HR}=$ hazard ratio, $\mathrm{CI}=$ confidence interval, TAP = total alkaline phosphate, and PTH intact parathyroid hormone. Adjusted for age, phosphate, calcium, $\mathrm{PTH}$, TAP, diabetes, systolic BP, 25-OH vitamin D, alanine transaminase and albumin, and serum calcium categories based on KDOQI reference range.

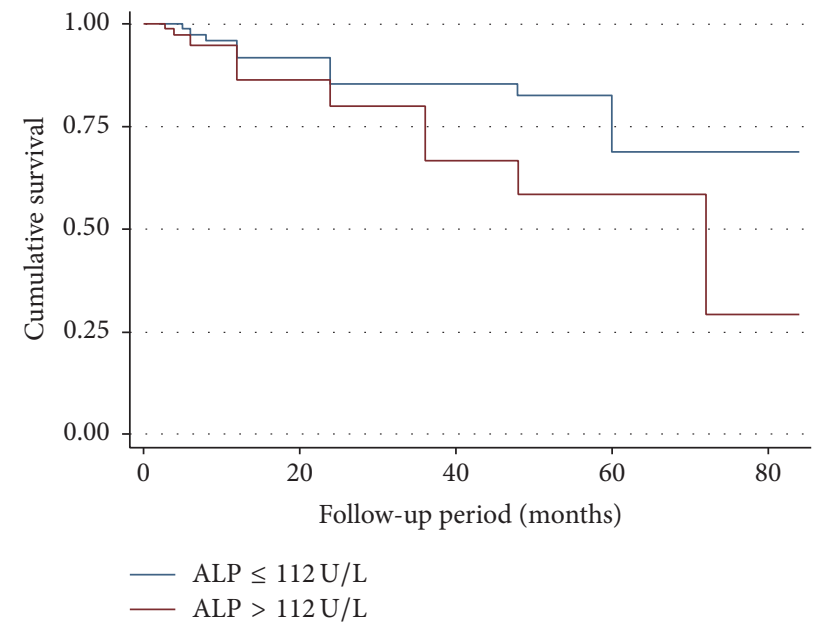

Figure 1: Kaplan Meier curve comparing patients in the high alkaline phosphatase to low alkaline phosphatase group $(P=0.01)$.

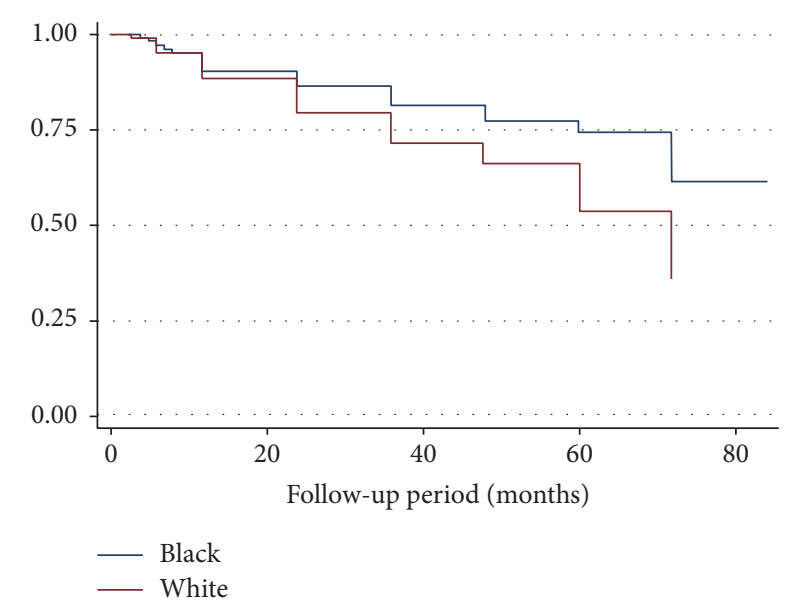

FIGURE 2: Kaplan Meier survival curve between black and white $(P=$ $0.004)$.

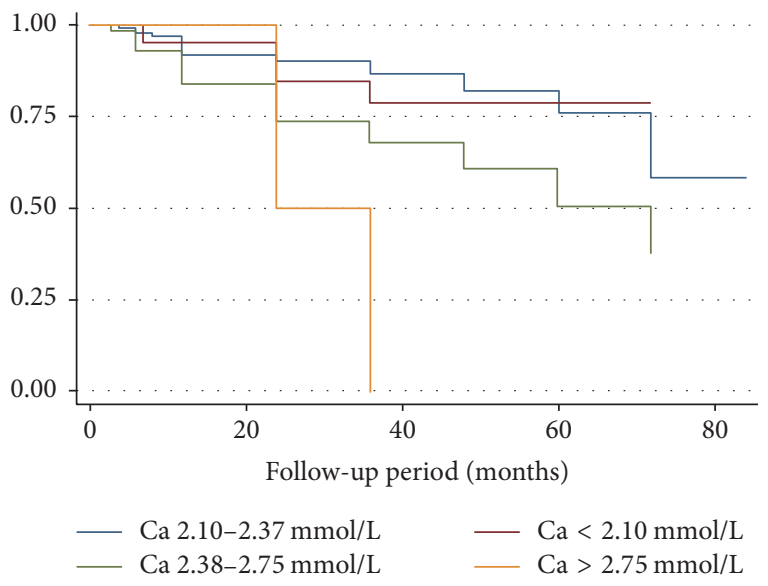

FIgURE 3: Kaplan Meier survival curves for different categories of calcium $(P=0.02)$. Calcium categories based on KDOQI reference range.

between elevated levels of TAP and mortality in the general population [21]. This further supports the notion that TAP is more than a marker of high bone turnover and may be a reliable predictor of mortality.

The mechanisms for this association have been linked to enhanced vascular calcification by high levels of serum TAP through hydrolysis of pyrophosphate or activation of apatite crystal formation [22]. In addition to vascular calcification, elevated levels of TAP have been associated with high $\mathrm{C}$ reactive protein, insulin resistance, and $25-\mathrm{OH}$ vitamin $\mathrm{D}$ deficiency [23-26]. In contrast to our study, we found no significant difference in the mean levels of $25-\mathrm{OH}$ vitamin $\mathrm{D}$ between patients with high TAP and low TAP.

Despite the variations in the cut-off points for defining hypercalcaemia by various studies, hypercalcaemia has been consistently associated with increased risk for mortality in haemodialysis patients $[12,18,27]$. Consistent with our finding, a linear relation was observed between higher calcium 
categories and increased risk of death $[12,18]$. In a large global representation of $\mathrm{HD}$ patients including the three phases of the dialysis outcomes and practice patterns study (DOPPSI, II and III) with $25,588 \mathrm{HD}$ patients, calcium levels greater than $10.0 \mathrm{mg} / \mathrm{dL}(>2.5 \mathrm{mmol} / \mathrm{L})$ were significantly associated with greater risk of all cause and cardiovascular mortality in both baseline and time dependent models [27]. The reasons for this consistent association could be linked to acceleration of arterial calcification by hypercalcaemia [28, 29]. Besides vascular calcification, high levels of calcium, but not high PTH, have been associated with poor mental health in MHD patients [30]. In contrast, studies relating to hypocalcaemia and risk of death have yielded contradictory reports. Lowrie and Lew [31] were the first to establish the association of increased mortality with calcium levels $<9.0 \mathrm{mg}$ in over $12,000 \mathrm{HD}$ patients, while in another large study from the US involving 40, $538 \mathrm{HD}$ patients, the mortality risk with low serum calcium levels was attenuated after adjusting for confounding variables [18]. In the dialysis outcomes and practice patterns study [32], serum calcium levels $<7.8 \mathrm{mg}$ were associated with lower mortality risk. In agreement with DOPPS, we found a similar trend, though not statistically significant, with serum calcium levels below $2.12 \mathrm{mmol} / \mathrm{L}$.

Hypercalcaemia is an undesirable effect associated with the use of calcium based phosphate binders and vitamin $\mathrm{D}$ analogues in controlling secondary hyperparathyroidism. This may likely have accounted for the lower levels of PTH seen in our category of patients with calcium levels above $2.75 \mathrm{mmol} / \mathrm{L}$. Although cinacalcet which is one of the newer drugs that effectively lowers PTH without raising serum calcium levels recently became available in South Africa, it is quite expensive, thus limiting its use to a few of our patients. In addition, the higher mean phosphate level in this group of patients is likely due to the concomitant use of alfacalcidol that enhances intestinal absorption of calcium and phosphate.

A notable finding in the current study is that white patients have a poor survival rate compared to black patients. This finding is consistent with recent emerging data from the USA that reported better survival in black patients compared with white patients on MHD [10]. The reasons underlying this racial survival benefit remain unclear, and several studies have proposed explanations for the better survival of black MHD patients compared to whites. A large US observational study reported that the widely perceived survival advantage for black dialysis patients applies only to older adults, with a reversal of the higher risk of death in the younger age group ( $<50$ years) [33]. This is contrary to several studies including the current study, where the risk persisted after adjusting for the significantly higher mean age in the white patients [34, 35]. Indeed, the better survival in black patients persisted in a study that comprehensively adjusted for demographics and dialysis modality among several other cofounding variables [34].

Another important observation we made in this study was that white patients had significantly higher levels of serum albumin. We expected this to give white patients a survival benefit. However, the reason for this reversal could likely be explained by a finding from a previous study where markers of worse nutritional status (hypoalbuminemia) or smaller muscle mass and increased body fat in African American patients correlated less strongly with mortality than in whites [36]. Additionally, studies have criticized the use of serum albumin in CKD patients as a marker of nutritional status as inappropriate $[37,38]$. In fact, the hazard ratio becomes accentuated after adjusting for serum albumin suggesting that the effect of race on mortality is likely to be through other mechanisms besides nutritional status.

In line with previous studies $[33,39]$, black patients had higher median intact PTH though this was not statistically significant. Some studies have reported survival benefit with active vitamin $\mathrm{D}$ therapy and that black patients are more likely to receive active vitamin agents due to higher $\mathrm{PTH}$ compared to white patients [40, 41]. However, it is unlikely that treatment with vitamin $\mathrm{D}$ alone may explain the racial survival paradox that has existed for several years. Additionally, reports relating to PTH levels have been controversial and studies are divided on which levels are associated with increased mortality. Similar to earlier $[17,18,42]$ and more recent studies $[10,43]$, we did not find significant association of mortality with severe hyperparathyroidism. On the other hand, studies that have shown significant associations are not unified on what levels of PTH are associated with increased mortality. Therefore, randomized control trials are needed to show the effect of treatment on PTH levels that are associated with favorable clinical outcomes.

Our findings should be considered in the context of the following limitations. Firstly, the retrospective nature of this study could not allow us to make causal associations between markers of mineral bone disease and study outcome (death). In addition, the use of a single baseline laboratory measurement precludes the performance of time dependent Cox analysis to account for variations in the biochemical markers on the impact of death over a period of time. However, few studies have shown no significant difference between the baseline and time dependent Cox analysis [12].

Secondly, the relatively small sample size precludes generalizability of our findings to African HD patients. Thus, there is a need for multicentre studies in Africa, to provide robust data on this important clinical entity (CKD-MBD) in African HD patients.

Thirdly, similar to several observational studies we could not account for residual confounding variables. For instance, aside from diabetes mellitus, other comorbid conditions could not be ascertained. However, part of the exclusion criteria was to avoid patients with some coexisting conditions that are known as potential confounders.

The strengths of this study lie in the heterogeneous nature of our study population (black and white patients) in an African setting which has allowed comparisons of data not only for Black Africans with Black Americans, but also between whites in Africa and USA/Europe. To our knowledge, this is the first study in Sub-Saharan Africa that has given important insights regarding the impact of serum alkaline phosphatase, calcium, and race on mortality in African MHD patients.

In summary, high TAP, hypercalcaemia, and white race are associated with increased risk of death in MHD patients, 
thus, reaffirming the need to pay more attention to the two modifiable risk factors (calcium and TAP) in the management of CKD-MBD.

\section{Ethical Approval}

All procedures performed in this study were in accordance with the ethical standards of the institutional and/or national research committee and with the 1964 Helsinki Declaration and its later amendments or comparable ethical standards. The research protocol was approved by the Health Research and Ethics committee (HREC) of the University of the Witwatersrand; clearance certificate number is M141016.

\section{Competing Interests}

The authors declare that they have no conflict of interests.

\section{Acknowledgments}

This study was partly supported by grants from the AstraZeneca Research Trust and the National Kidney Foundation of South Africa (NKFSA) ADCOCK INGRAM research grant.

\section{References}

[1] W. L. Lau and K. Kalantar-Zadeh, "Towards the revival of alkaline phosphatase for the management of bone disease, mortality and hip fractures," Nephrology Dialysis Transplantation, vol. 29, no. 8, pp. 1450-1452, 2014.

[2] Kidney Disease: Improving Global Outcomes (KDIGO) CKDMBD Work Group, "KDIGO clinical practice guideline for the diagnosis, evaluation, prevention, and treatment of chronic kidney disease-mineral and bone disorder (CKD-MBD)," Kidney International, vol. 76, supplement 113, pp. S1-S130, 2009.

[3] K. A. Lomashvili, P. Garg, S. Narisawa, J. L. Millan, and W. C. O’Neill, "Upregulation of alkaline phosphatase and pyrophosphate hydrolysis: potential mechanism for uremic vascular calcification," Kidney International, vol. 73, no. 9, pp. 1024-1030, 2008.

[4] W. C. O’Neill, "Pyrophosphate, alkaline phosphatase, and vascular calcification," Circulation Research, vol. 99, no. 2, article e2, 2006.

[5] M. K. Sigrist, M. W. Taal, P. Bungay, and C. W. McIntyre, "Progressive vascular calcification over 2 years is associated with arterial stiffening and increased mortality in patients with stages 4 and 5 chronic kidney disease," Clinical Journal of the American Society of Nephrology, vol. 2, no. 6, pp. 1241-1248, 2007.

[6] R. Shantouf, C. P. Kovesdy, Y. Kim et al., "Association of serum alkaline phosphatase with coronary artery calcification in maintenance hemodialysis patients," Clinical Journal of the American Society of Nephrology, vol. 4, no. 6, pp. 1106-1114, 2009.

[7] S. V. Badve, L. Zhang, J. S. Coombes et al., "Association between serum alkaline phosphatase and primary resistance to erythropoiesis stimulating agents in chronic kidney disease: a secondary analysis of the HERO trial," Canadian Journal of Kidney Health and Disease, vol. 2, no. 33, 2015.
[8] K. C. Norris, K. Kalantar-Zadeh, and J. D. Kopple, "The role of race in survival among patients undergoing dialysis," Nephrology News \& Issues, vol. 25, no. 13, pp. 13-16, 2011.

[9] G. Yan, K. C. Norris, A. J. Yu et al., "The relationship of age, race, and ethnicity with survival in dialysis patients," Clinical Journal of the American Society of Nephrology, vol. 8, no. 6, pp. 953-961, 2013.

[10] J. J. Scialla, R. S. Parekh, J. A. Eustace et al., "Race, mineral homeostasis and mortality in patients with end-stage renal disease on dialysis," American Journal of Nephrology, vol. 42, no. 1, pp. 25-34, 2015.

[11] C. Robinson-Cohen, A. N. Hoofnagle, J. H. Ix et al., "Racial differences in the association of serum 25-hydroxyvitamin D concentration with coronary heart disease events," The Journal of the American Medical Association, vol. 310, no. 2, pp. 179-188, 2013.

[12] J. Floege, J. Kim, E. Ireland et al., "Serum iPTH, calcium and phosphate, and the risk of mortality in a European haemodialysis population," Nephrology Dialysis Transplantation, vol. 26, no. 6, pp. 1948-1955, 2011.

[13] B. O. Lightfoot, R. J. Caruana, L. L. Mulloy, and M. E. Fincher, "Simple formula for calculating normalized protein catabolic rate (NPCR) in haemodialysis (HD) patients (abstract)," Journal of the American Society of Nephrology, vol. 4, p. 363, 1993.

[14] M. J. Blayney, R. L. Pisoni, J. L. Bragg-Gresham et al., "High alkaline phosphatase levels in hemodialysis patients are associated with higher risk of hospitalization and death," Kidney International, vol. 74, no. 5, pp. 655-663, 2008.

[15] J. Beige, R. Wendt, M. Girndt, K.-H. Queck, R. Fiedler, and P. Jehle, "Association of serum alkaline phosphatase with mortality in non-selected european patients with ckd5d: an observational, three-centre survival analysis," BMJ Open, vol. 4, no. 2, Article ID e004275, 2014.

[16] D. L. Regidor, C. P. Kovesdy, R. Mehrotra et al., "Serum alkaline phosphatase predicts mortality among maintenance hemodialysis patients," Journal of the American Society of Nephrology, vol. 19, no. 11, pp. 2193-2203, 2008.

[17] K. Kalantar-Zadeh, N. Kuwae, D. L. Regidor et al., "Survival predictability of time-varying indicators of bone disease in maintenance hemodialysis patients," Kidney International, vol. 70, no. 4, pp. 771-780, 2006.

[18] G. A. Block, P. S. Klassen, J. M. Lazarus, N. Ofsthun, E. G. Lowrie, and G. M. Chertow, "Mineral metabolism, mortality, and morbidity in maintenance hemodialysis," Journal of the American Society of Nephrology, vol. 15, no. 8, pp. 2208-2218, 2004.

[19] J. Cunningham and J. Silver, "CKD-MBD: comfort in the trough of the U," Nephrology Dialysis Transplantation, vol. 26, no. 6, pp. 1764-1766, 2011.

[20] S. Beddhu, X. Ma, B. Baird, A. K. Cheung, and T. Greene, "Serum alkaline phosphatase and mortality in African Americans with chronic kidney disease," Clinical Journal of the American Society of Nephrology, vol. 4, no. 11, pp. 1805-1810, 2009.

[21] M. Tonelli, G. Curhan, M. Pfeffer et al., "Relation between alkaline phosphatase, serum phosphate, and all-cause or cardiovascular mortality," Circulation, vol. 120, no. 18, pp. 1784-1792, 2009.

[22] M. Schoppet and C. M. Shanahan, "Role for alkaline phosphatase as an inducer of vascular calcification in renal failure?" Kidney International, vol. 73, no. 9, pp. 989-991, 2008. 
[23] B. M. Y. Cheung, K. L. Ong, R. V. Cheung et al., "Association between plasma alkaline phosphatase and C-reactive protein in Hong Kong Chinese," Clinical Chemistry and Laboratory Medicine, vol. 46, no. 4, pp. 523-527, 2008.

[24] A. J. G. Hanley, K. Williams, A. Festa, L. E. Wagenknecht, R. B. D’Agostino Jr., and S. M. Haffner, "Liver markers and development of the metabolic syndrome: the insulin resistance atherosclerosis study," Diabetes, vol. 54, no. 11, pp. 3140-3147, 2005.

[25] J. R. Chaudhuri, K. R. Mridula, A. Anamika et al., "Deficiency of 25-hydroxyvitamin d and dyslipidemia in Indian subjects," Journal of Lipids, vol. 2013, Article ID 623420, 7 pages, 2013.

[26] P. Lips, T. Duong, A. Oleksik et al., "A global study of vitamin D status and parathyroid function in postmenopausal women with osteoporosis: baseline data from the multiple outcomes of raloxifene evaluation clinical trial," The Journal of Clinical Endocrinology \& Metabolism, vol. 86, no. 3, pp. 1212-1221, 2001.

[27] F. Tentori, M. J. Blayney, J. M. Albert et al., "Mortality risk for dialysis patients with different levels of serum calcium, phosphorus, and PTH: The Dialysis Outcomes and Practice Patterns Study (DOPPS)," American Journal of Kidney Diseases, vol. 52, no. 3, pp. 519-530, 2008.

[28] G. M. London, S. J. Marchais, A. P. Guérin, P. Boutouyrie, F. Métivier, and M.-C. de Vernejoul, "Association of bone activity, calcium load, aortic stiffness, and calcifications in ESRD," Journal of the American Society of Nephrology, vol. 19, no. 9, pp. 1827-1835, 2008.

[29] M. Noordzij, E. M. Cranenburg, L. F. Engelsman et al., "Progression of aortic calcification is associated with disorders of mineral metabolism and mortality in chronic dialysis patients," Nephrology Dialysis Transplantation, vol. 26, no. 5, pp. 16621669, 2011.

[30] M. Tanaka, S. Yamazaki, Y. Hayashino et al., "Hypercalcaemia is associated with poor mental health in haemodialysis patients: results from Japan DOPPS," Nephrology Dialysis Transplantation, vol. 22, no. 6, pp. 1658-1664, 2007.

[31] E. G. Lowrie and N. L. Lew, "Death risk in hemodialysis patients: the predictive value of commonly measured variables and an evaluation of death rate differences between facilities," American Journal of Kidney Diseases, vol. 15, no. 5, pp. 458-482, 1990.

[32] E. W. Young, J. M. Albert, S. Satayathum et al., "Predictors and consequences of altered mineral metabolism: the Dialysis Outcomes and Practice Patterns Study," Kidney International, vol. 67, no. 3, pp. 1179-1187, 2005.

[33] L. M. Kucirka, M. E. Grams, J. Lessler et al., "Association of race and age with survival among patients undergoing dialysis," The Journal of the American Medical Association, vol. 306, no. 6, pp. 620-626, 2011.

[34] E. Streja, C. P. Kovesdy, M. Z. Molnar et al., "Role of nutritional status and inflammation in higher survival of African American and hispanic hemodialysis patients," American Journal of Kidney Diseases, vol. 57, no. 6, pp. 883-893, 2011.

[35] D. C. Crews, S. M. Sozio, Y. Liu, J. Coresh, and N. R. Powe, "Inflammation and the paradox of racial differences in dialysis survival," Journal of the American Society of Nephrology, vol. 22, no. 12, pp. 2279-2286, 2011.

[36] U. Feroze, N. Noori, C. P. Kovesdy et al., "Quality-of-life and mortality in hemodialysis patients: roles of race and nutritional status," Clinical Journal of the American Society of Nephrology, vol. 6, no. 5, pp. 1100-1111, 2011.
[37] A. N. Friedman and S. Z. Fadem, "Reassessment of albumin as a nutritional marker in kidney disease," Journal of the American Society of Nephrology, vol. 21, no. 2, pp. 223-230, 2010.

[38] W. E. Mitch, "Malnutrition: a frequent misdiagnosis for hemodialysis patients," The Journal of Clinical Investigation, vol. 110, no. 4, pp. 437-439, 2002.

[39] O. M. Gutiérrez, W. R. Farwell, D. Kermah, and E. N. Taylor, "Racial differences in the relationship between vitamin $\mathrm{D}$, bone mineral density, and parathyroid hormone in the National Health and Nutrition Examination Survey," Osteoporosis International, vol. 22, no. 6, pp. 1745-1753, 2011.

[40] M. Wolf, J. Betancourt, Y. Chang et al., "Impact of activated vitamin $\mathrm{D}$ and race on survival among hemodialysis patients," Journal of the American Society of Nephrology, vol. 19, no. 7, pp. 1379-1388, 2008.

[41] M. L. Melamed, J. A. Eustace, L. Plantinga et al., "Changes in serum calcium, phosphate, and PTH and the risk of death in incident dialysis patients: a longitudinal study," Kidney International, vol. 70, no. 2, pp. 351-357, 2006.

[42] R. Wald, M. J. Sarnak, H. Tighiouart et al., "Disordered mineral metabolism in hemodialysis patients: an analysis of cumulative effects in the hemodialysis (HEMO) Study," American Journal of Kidney Diseases, vol. 52, no. 3, pp. 531-540, 2008.

[43] M. Fukagawa, R. Kido, H. Komaba et al., "Abnormal mineral metabolism and mortality in hemodialysis patients with secondary hyperparathyroidism: evidence from marginal structural models used to adjust for time-dependent confounding," American Journal of Kidney Diseases, vol. 63, no. 6, pp. 979-987, 2014. 


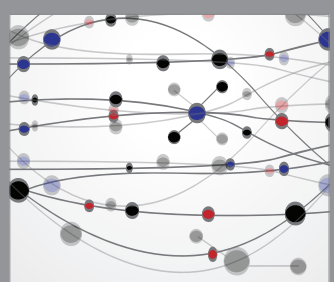

The Scientific World Journal
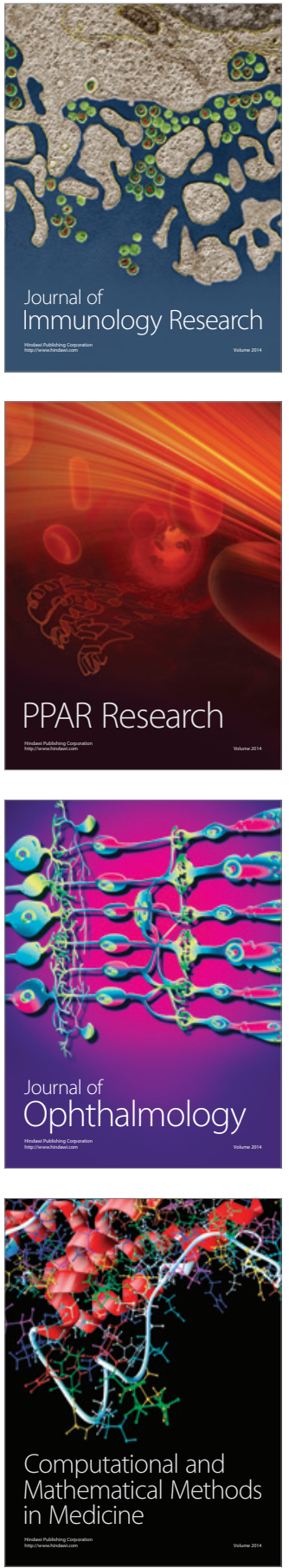

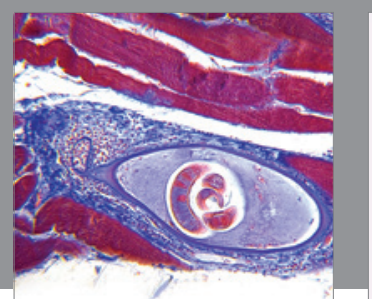

Gastroenterology Research and Practice
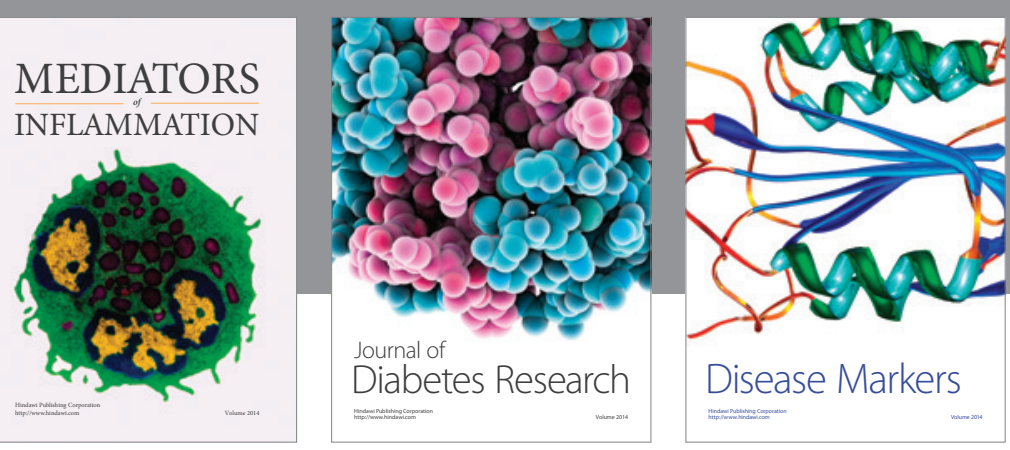

Disease Markers

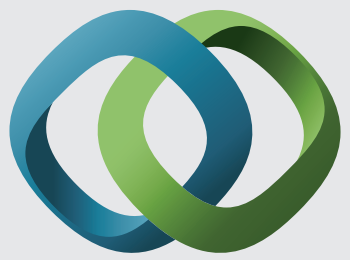

\section{Hindawi}

Submit your manuscripts at

https://www.hindawi.com
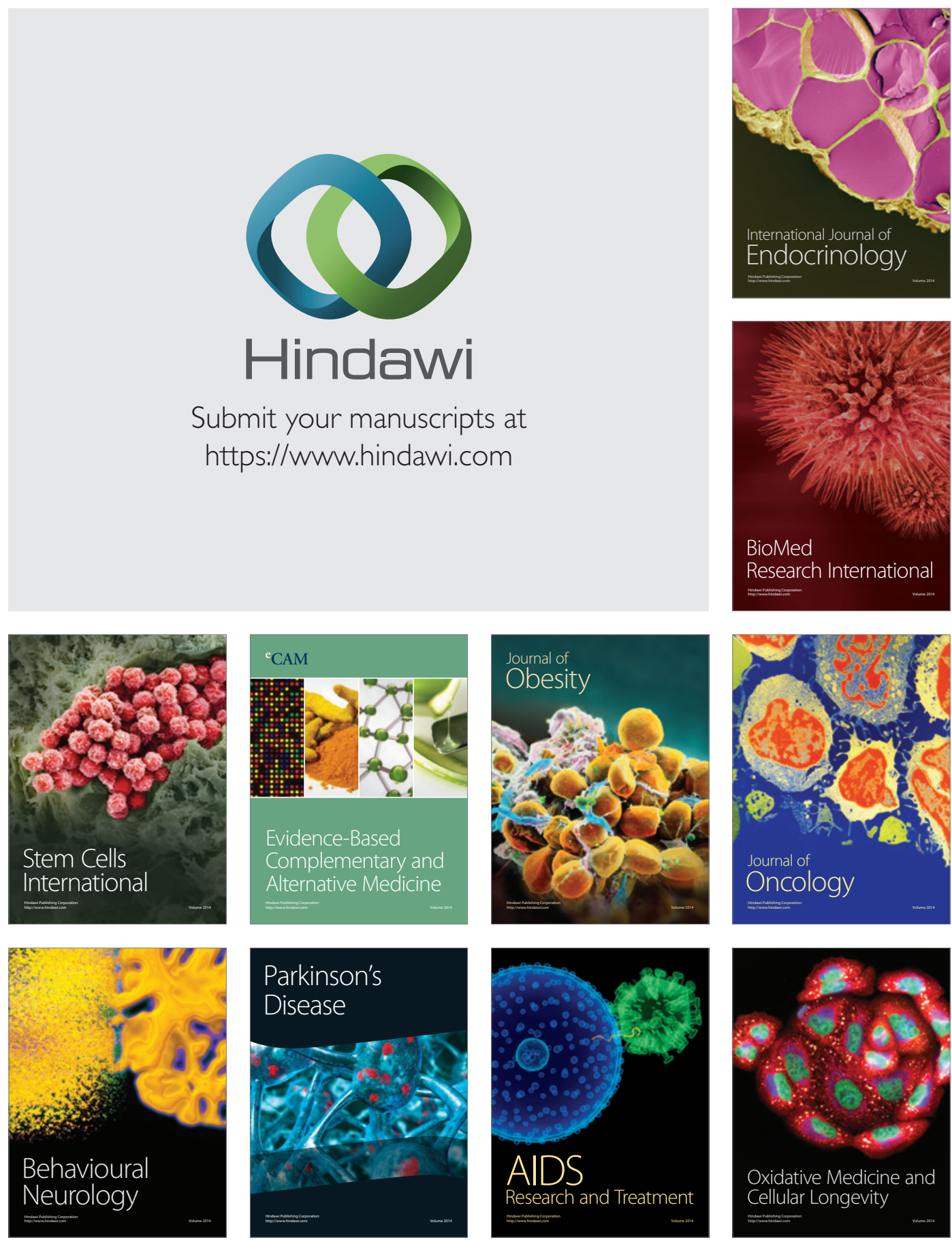